\title{
A Clinico-Hematological Study of Influenza Virus Infection
}

\author{
Shivani Shenoy K', Raj Shekhar², Mary Mathew ${ }^{3}$, G Arun Kumar ${ }^{4}$ \\ ${ }^{1}$ 3rd MBBS (7th Sem), Kasturba Medical College, Manipal - 576104, Manipal University, Karnataka, India, ${ }^{23 r d}$ MBBS (7th Sem), Kasturba Medical College, \\ Manipal - 576104, Manipal University, Karnataka, India, ${ }^{3}$ Professor, Department of Pathology, Kasturba Medical College, Manipal - 576104, Manipal \\ University, Karnataka, India, ${ }^{4}$ Professor and Head, Manipal Centre for Virus Research, Manipal - 576104, Manipal University, Karnataka, India.
}

\section{Abstract}

Background: Influenza is a seasonal infectious viral disease which accounts for approximately 3-5 million cases of severe illness and 250,000 to 500,000 deaths in a yearly outbreak. The objectives of our study were to study the various clinical presentation of influenza infection and to correlate the demographic data and clinical symptoms with hematological parameters. Subjects and Methods: 95 cases which were positive by One-step RT-PCR were included in the study. Elevation of serum transaminase levels, thrombocytopenia and raised creatinine levels are important parameters which mandates vigilant follow up in patients with influenza infection. Results: The most common symptoms were fever in $88.42 \%$ and cough in $88.42 \%$ of cases. $51.57 \%$ of patients presented with anemia on admission. $11.5 \%$ of patients had thrombocytopenia of which $36.36 \%$ had elevated liver enzymes. $35.78 \%$ of cases had leukocytosis of which $32.35 \%$ had elevated liver enzymes. $15.78 \%$ of patients had raised creatinine levels. Conclusion: Authors suggested that elevation of serum transaminase levels, thrombocytopenia and raised creatinine levels are important parameters which mandates vigilant follow up in patients with influenza infection.

Keywords: Influenza, Hematological parameters, Liver enzymes.

Corresponding Author: Raj Shekhar, 3rd MBBS (7th Sem), Kasturba Medical College, Manipal - 576104, Manipal University, Karnataka, India.

Received: October 2019

Accepted: October 2019

\section{Introduction}

Influenza is an infectious viral disease caused by the RNA virus - influenza virus (A, B and C). The virus spreads mainly through direct transmission-coughing or sneezing into eyes, nose or mouth of another person. It is also transmitted through the airborne route and hand-to-eye/handto-mouth route. Approximately $33 \%$ of people with influenza are asymptomatic. In those who were symptomatic, the most common symptoms include: a high fever, extreme chills and rigor, nasal congestion, runny nose, cough, sore throat, muscle pains, body ache, tearing and reddened eyes, petechial rash, headache and fatigue. These symptoms typically begin two days after exposure to the virus and most last less than a week. In children, there may be gastrointestinal symptoms like nausea, vomiting, abdominal pain and diarrhea. ${ }^{[1]}$

Influenza is an acute respiratory illness that has been recognised since the 16th century and spreads rapidly through communities in outbreaks. Two forms of influenza occur globally: epidemic (seasonal or interpandemic) influenza caused by influenza A and B viruses, and sporadic pandemics caused by influenza viruses. These epidemiological forms of influenza result from distinct mechanisms of antigenic variation in the surface glycoproteins of the virus, referred to as antigenic drift and antigenic shift.
Complications of influenza may include viral pneumonia, secondary bacterial pneumonia and sinus infections. Influenza spreads around the world in a yearly outbreak, resulting in about three to five million cases of severe illness and about 250,000 to 500,000 deaths..$^{[2,3,4,5]}$ The aim of this study was to study the various clinical presentation of influenza infection and to correlate the demographic data and clinical symptoms with hematological parameters.

\section{Subjects and Methods}

The present retrospective study included cases of Influenza conducted from April 1, 2016, until August 31, 2016 at Kasturba Hospital, Manipal. Study proceeded after the approval of Department Scientific Committee and Institutional Ethics Committee. All patients who met with the inclusion criteria (Only cases of influenza virus infection confirmed by One-step real time PCR) were included in the study. 95 patients fulfilled the inclusion criteria and their records were extracted for collection of clinical and laboratory data.

Data such as name, age, gender, clinical features, etc. was retrieved from case files. Results of routine complete blood count, liver function tests and renal function tests performed on hospitalization before commencing drug therapy. Confidentiality was maintained by not disclosing the identity of the patients. Statistical analysis was performed using SPSS 16. The demographic, clinical and laboratory data were 
evaluated and presented descriptively. Descriptive statistics (percentage, mean and standard deviation) were used primarily to summarize and describe the data.

\section{Results}

A total of 72 cases admitted to our hospital between Jan 2017 to Dec 2018 were statically analyzed. Most of the dengue cases presented during the month of August and September which depicts the role of rainy season for case clustering during that season.

\section{Table 1: Distribution of patients}

\begin{tabular}{|c|c|c|}
\hline \multicolumn{3}{|c|}{ Total- 95} \\
\hline Gender & Male & Female \\
\hline Number & $23(24.21 \%)$ & $72(75.78 \%)$ \\
\hline
\end{tabular}

[Table 1] shows that out of 95 patients, males were 23 $(24.21 \%)$ and females were $72(75.78 \%)$.

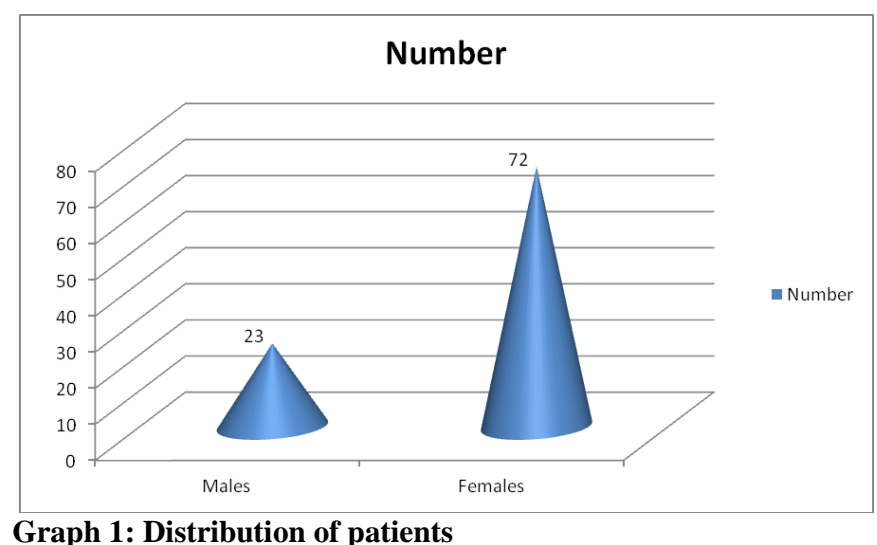

Graph 1: Distribution of patients

Table 2: Clinical features in patients

\begin{tabular}{|c|c|c|}
\hline Clinical features & Number & P value \\
\hline Fever & 84 & \multirow[t]{14}{*}{0.01} \\
\hline Cough & 84 & \\
\hline Running nose & 37 & \\
\hline Dyspnea & 25 & \\
\hline Sore throat & 20 & \\
\hline Nausea & 3 & \\
\hline Vomiting & 9 & \\
\hline Diarrhea & 2 & \\
\hline Fatigue/ malaise & 27 & \\
\hline Headache & 21 & \\
\hline Abdominal pain & 5 & \\
\hline Dizziness & 4 & \\
\hline Chest pain & 13 & \\
\hline Joint pain & 3 & \\
\hline
\end{tabular}

[Table 2], Graph II shows that common symptoms were fever and cough in 84 patients each, running nose in 37, dyspnea in 25, sore throat in 20, Fatigue/ malaise in 27 and headache in 21 . The difference was significant $(\mathrm{P}<0.05)$.

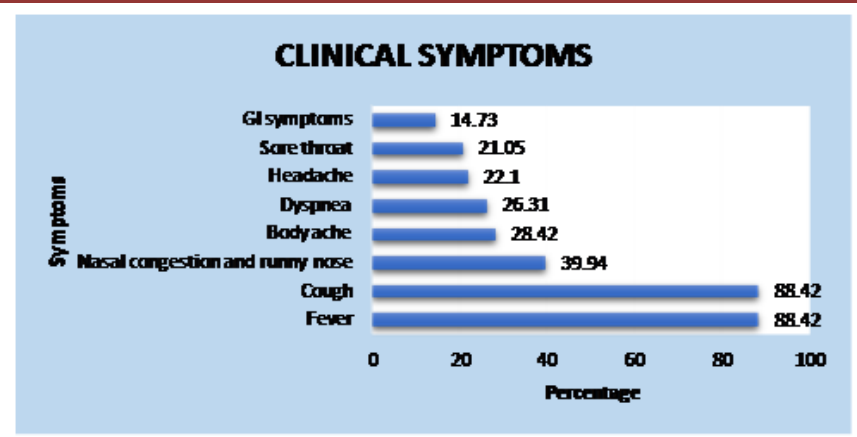

Graph 2:

Table 3: Hematological parameters and liver enzymes

[Table 3] shows that Anemia, thrombocytopenia and leucopenia was present in 51.57\% ( $\mathrm{n}=49), 11.57 \%(\mathrm{n}=11)$ and $4.21 \%(\mathrm{n}=4)$ respectively. Leucocytosis was present in $35.78 \%(n=34)$. Serum urea and creatinine was elevated in $10.52 \%(\mathrm{n}=10)$ and $15.78 \%(\mathrm{n}=15)$ respectively. Elevated liver enzymes like AST in $26.31 \%(\mathrm{n}=25)$, ALT in $8.42 \%$ $(n=8)$ and ALP in $3.15 \%(n=3)$ was seen.

Table 4: Correlation of liver enzyme elevation versus hematological parameters

\begin{tabular}{|l|l|l|l|l|}
\hline $\begin{array}{l}\text { Elevated } \\
\text { liver } \\
\text { enzymes }\end{array}$ & $\begin{array}{l}\text { Thrombocyto } \\
\text { penia present } \\
(\%)\end{array}$ & $\begin{array}{l}\text { Thrombocytop } \\
\text { enia absent } \\
(\%)\end{array}$ & $\begin{array}{l}\text { Leucocyto } \\
\text { sis present } \\
(\%)\end{array}$ & $\begin{array}{l}\text { Leucocyto } \\
\text { sis absent } \\
(\%)\end{array}$ \\
& $\begin{array}{l}88.57 \%(\mathrm{n}=84) \\
(\mathrm{n}=11)\end{array}$ & $\begin{array}{l}35.78 \% \\
(\mathrm{n}=34)\end{array}$ & $\begin{array}{l}64.21 \% \\
(\mathrm{n}=61)\end{array}$ \\
\hline AST & $36.36(\mathrm{n}=4)$ & $25(\mathrm{n}=21)$ & $\begin{array}{l}32.35 \\
(\mathrm{n}=11)\end{array}$ & $\begin{array}{l}22.95 \\
(\mathrm{n}=14)\end{array}$ \\
\hline ALT & $18.18(\mathrm{n}=2)$ & $7.14(\mathrm{n}=6)$ & $\begin{array}{l}11.76 \\
(\mathrm{n}=4)\end{array}$ & $6.55(\mathrm{n}=4)$ \\
\hline ALP & $18.18(\mathrm{n}=2)$ & $1.19(\mathrm{n}=1)$ & $5.68(\mathrm{n}=2)$ & $1.63(\mathrm{n}=1)$ \\
\hline
\end{tabular}

[Table 4] shows that of those who had thrombocytopenia $11.57 \%(n=11), 36.36 \%(n=4)$ had elevated liver enzymes as compared to $25 \% \quad(\mathrm{n}=21)$ who did not have thrombocytopenia. Of those who had leukocytosis $35.78 \%$ $(n=34), 32.35 \% \quad(n=11)$ had elevated liver enzymes as compared to $22.95 \%(\mathrm{n}=14)$ who did not have leukocytosis. Of those who had elevated liver enzymes and abnormal hematological values, statistical analysis was done to see for their age groups.

Table 5: Correlation of clinical symptoms versus hematological parameters

\begin{tabular}{|l|l|l|l|l|}
\hline $\begin{array}{l}\text { Sympto } \\
\text { ms }\end{array}$ & $\begin{array}{l}\text { Thrombocyto } \\
\text { penia present } \\
(\boldsymbol{\%})\end{array}$ & $\begin{array}{l}\text { Thrombocyto } \\
\text { penia absent } \\
(\%)\end{array}$ & $\begin{array}{l}\text { Leucocyt } \\
\text { osis } \\
\text { present } \\
(\%)\end{array}$ & $\begin{array}{l}\text { Leucocyt } \\
\text { osis } \\
\text { absent } \\
(\%)\end{array}$ \\
\hline Fever & $11.57 \%(\mathrm{n}=11)$ & $88.42(\mathrm{n}=84)$ & $\begin{array}{l}35.78 \% \\
(\mathrm{n}=34)\end{array}$ & $\begin{array}{l}64.21 \% \\
(\mathrm{n}=61)\end{array}$ \\
\hline Cough & $100(\mathrm{n}=11)$ & $86.9(\mathrm{n}=73)$ & $\begin{array}{l}94.11 \\
(\mathrm{n}=32)\end{array}$ & $\begin{array}{l}88.52 \\
(\mathrm{n}=54)\end{array}$ \\
\hline Dyspnea & $36.36(\mathrm{n}=4)$ & $86.9(\mathrm{n}=73)$ & $\begin{array}{l}91.11 \\
(\mathrm{n}=31)\end{array}$ & $\begin{array}{l}86.88 \\
(\mathrm{n}=53)\end{array}$ \\
& & $25(\mathrm{n}=21)$ & $\begin{array}{l}38.23 \\
(\mathrm{n}=13)\end{array}$ & $\begin{array}{l}19.67 \\
(\mathrm{n}=12)\end{array}$ \\
\hline
\end{tabular}

[Table 5] shows that of those who had thrombocytopenia, 
$100 \%(\mathrm{n}=11)$ had fever and respiratory symptoms as compared to $86.9 \% \quad(n=73)$ who did not have thrombocytopenia. Of those who had leukocytosis, $91.11 \%$ $(n=31)$ had fever as compared to $22.95 \%(n=14)$ who did not have leukocytosis.

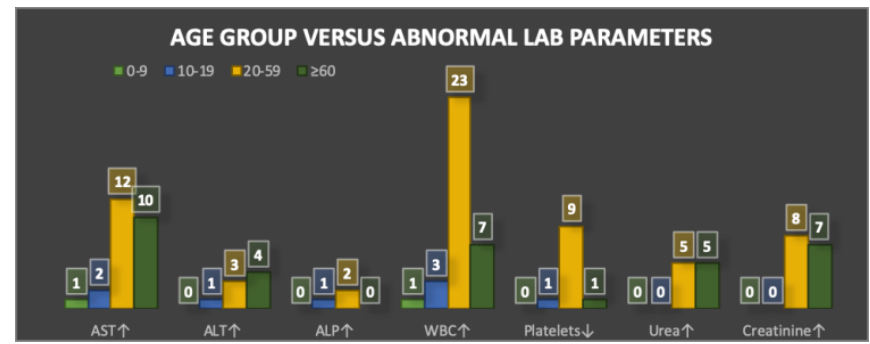

Graph 3: Age grouping of abnormal laboratory investigations

[Graph 3] shows that 0-9 years - Infancy and childhood, 1019 years - Adolescents, 20-59 years - Adults and $\geq 60-$ Old. Most of them belonged to adult age group.

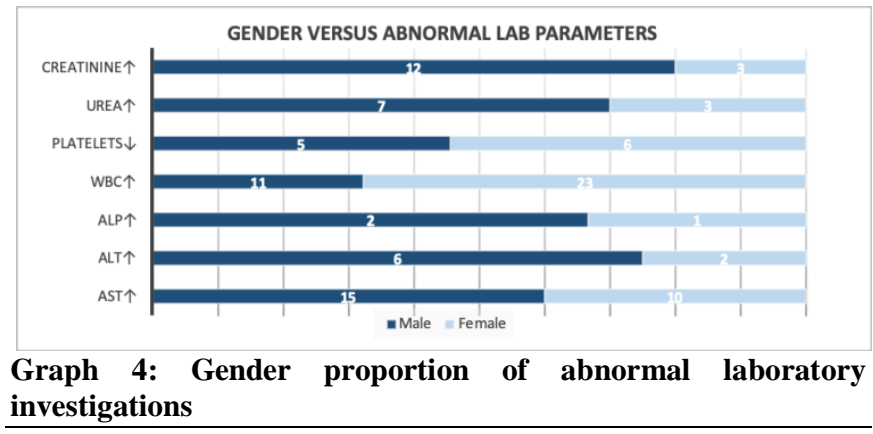

[Graph 4] shows that increase creatinine level, urea, WBC, ALP, ALT and AST was more prevalent in males than females.

\section{Discussion}

Influenza outbreaks are often first recognized in children presenting with febrile illness. An increase in hospital admissions and respiratory or circulatory deaths are reported as the epidemic progresses. A typical influenza epidemic peaks within 2-3 weeks of onset and lasts 5-6 weeks. ${ }^{[6]}$ Seasonal influenza accounts for thousands of deaths and hospital admissions annually in the European Union and the USA, with an even greater impact in developing countries. ${ }^{[7]}$ Influenza epidemics in which $\mathrm{H} 3 \mathrm{~N} 2$ strains predominate are associated with the highest overall morbidity and mortality. The panel summarises the risk factors associated with severe illness, complications, or mortality due to influenza. ${ }^{[8]}$

We found that majority of patients came with fever and respiratory symptoms. Fever was seen in 84 patients $(88.42 \%)$ out of which 65 had associated chills. The most predominant respiratory symptom was cough, which was seen in 84 patients $(88.42 \%)$ ) 53 patients out 84 had dry cough as compared to 31 with expectoration. Other respiratory symptoms like runny nose and nasal congestion was present in 37 patients (38.94\%), dyspnea in 25 patients $(26.31 \%)$ and sore throat in 20 patients $(21.05 \%)$. Gastrointestinal symptoms like nausea (3 patients), vomiting (9 patients) and diarrhea ( 2 patients) were seen in a total of 14 patients (14.73\%). Other symptoms like fatigue and malaise was seen in 27 patients $(28.24 \%)$, headache in 21 patients $(22.1 \%)$, abdominal pain in 5 patients $(5.26 \%)$, dizziness in 4 patients $(4.1 \%)$, chest pain in 3 patients $(3.15 \%)$ and joint pain in 3 patients $(3.15 \%)$.

We found that Anemia, thrombocytopenia and leucopenia was present in $51.57 \%(\mathrm{n}=49), 11.57 \%(\mathrm{n}=11)$ and $4.21 \%$ $(n=4)$ respectively. Leucocytosis was present in $35.78 \%$ $(n=34)$. Serum urea and creatinine was elevated in $10.52 \%$ $(\mathrm{n}=10)$ and $15.78 \% \quad(\mathrm{n}=15)$ respectively. Elevated liver enzymes like AST in $26.31 \%(n=25)$, ALT in $8.42 \%(n=8)$ and ALP in $3.15 \%(n=3)$ was seen.

We found that of those who had elevated liver enzymes and abnormal hematological values, statistical analysis was done to see for gender proportion. Males had more abnormal laboratory parameters compared to females. The presentation of seasonal influenza ranges from an asymptomatic infection to a fulminant illness, depending on the characteristics of both the host and virus. Symptoms appear suddenly after an incubation period of 1-2 days and are characterized by various systemic features, including fever, chills, headache, myalgia, malaise, and anorexia, accompanied by respiratory symptoms, including non-productive cough, nasal discharge, and sore throat. Ocular symptoms can also be present and include photophobia, conjunctivitis, lacrimation, and pain with eye movement. ${ }^{[9]}$

Allyn et $\mathrm{al}^{[10]}$ reported two cases of severe influenza infection imported by tourist patients from their country of origin and developed during travel. No international recommendation exists concerning influenza vaccination before travel, and few countries recommend it for all travelers. Authors suggested that travel should be canceled when infectious signs are observed before departure. Influenza is a very common infection that is often benign, but sometimes very severe. The most severe cases include shock, acute respiratory distress syndrome (ARDS), myocarditis, rhabdomyolysis, and multiple organ failure. Management can require exceptional therapies, such as extracorporeal membrane oxygenation.

\section{Conclusion}

Authors suggested that elevation of serum transaminase levels, thrombocytopenia and raised creatinine levels are important parameters which mandates vigilant follow up in patients with influenza infection.

\section{References}

1. Paules, C., \& Subbarao, K. Influenza. The Lancet 2017; 390(10095), 697-708.

2. Cox NJ, Subbarao K. Global epidemiology of influenza: past and present. Annu Rev Med 2000; 51: 407-21.

3. Yang L, Chan KH, Suen LK, et al. Age-specific epidemic waves of influenza and respiratory syncytial virus in a subtropical city. Sci Rep 2015; 5: 10390

4. Barker WH, Mullooly JP. Pneumonia and influenza deaths during epidemics: implications for prevention. Arch Intern Med 1982; 142 $85-89$.

5. Biggerstaff M, Cauchemez S, Reed C, Gambhir M, Finelli L. Estimates of the reproduction number for seasonal, pandemic, and zoonotic influenza: a systematic review of the literature. BMC Infect Dis 2014 14: 480

6. Jayasundara K, Soobiah C, Thommes E, Tricco AC, Chit A. Natural attack rate of influenza in unvaccinated children and adults: a metaregression analysis. BMC Infect Dis 2014; 14: 670. 
7. Thompson WW, Shay DK, Weintraub E, et al. Influenza-associated hospitalizations in the United States. JAMA 2004; 292: 1333-40.

8. Molinari NA, Ortega-Sanchez IR, Messonnier ML, et al. The annual impact of seasonal influenza in the US: measuring disease burden and costs. Vaccine 2007; 25: 5086-96.

9. Lafond KE, Nair H, Rasooly MH, et al. Global role and burden of influenza in pediatric respiratory hospitalizations, 1982-2012: a systematic analysis. PLoS Med 2016; 13: 1001977

10. Allyn J, Brottet E, Antok E, Dangers L, Persichini R, Coolen-Allou N, Roquebert B, Allou N, Vandroux D. Case Report: Severe Imported Influenza Infections Developed during Travel in Reunion Island. The American journal of tropical medicine and hygiene. 2017 Dec 6;97(6):1943-4

Copyright: () the author(s), 2019. It is an open-access article distributed under the terms of the Creative Commons Attribution License (CC BY 4.0), which permits authors to retain ownership of the copyright for their content, and allow anyone to download, reuse, reprint, modify, distribute and/or copy the content as long as the original authors and source are cited.

How to cite this article: K Shenoy S, Shekhar R, Mathew M, Kumar GA. A Clinico-Hematological Study of Influenza Virus Infection .Acad. J Med. 2019;2(2):24-27.

DOI: dx.doi.org/10.21276/ajm.2019.2.2.8

Source of Support: Nil, Conflict of Interest: None declared. 